\title{
Interleukin 1 Induces a Shock-like State in Rabbits \\ Synergism with Tumor Necrosis Factor and the Effect of Cyclooxygenase Inhibition
}

\author{
Seijiro Okusawa, "‡ Jeffrey A. Gelfand," Takashi lkejima," Raymond J. Connolly,' and Charles A. Dinarello* \\ *Department of Medicine, Division of Geographic Medicine and Infectious Diseases, Tufts University and New England Medical \\ Center Hospital, Boston, Massachusetts 02111; ${ }^{\ddagger}$ Department of Surgery, Trauma Service, Massachusetts General Hospital, Boston, \\ Massachusetts 02114; ' Department of Surgery, New England Medical Center Hospitals, Boston, Massachusetts 02111
}

\begin{abstract}
In addition to activating $\mathbf{T}$ and $\mathrm{B}$ lymphocytes, interleukin 1 (IL-1) induces several hematologic and metabolic changes typical of host responses to infection and injury. We now report a new biological property, namely, the induction of hypotension. Rabbits given a single intravenous injection of recombinant human IL-1-beta (5 $\mathrm{\mu g} / \mathrm{kg}$ ) rapidly developed decreased systemic arterial pressure, which reached the lowest levels after 50-60 min and slowly returned to pre-IL-1 values after $3 \mathrm{~h}$. Associated with the hypotension, systemic vascular resistance and central venous pressure fell, while cardiac output and heart rate increased. These responses were prevented by ibuprofen given $15 \mathrm{~min}$ before the IL-1. A bolus injection of IL-1 followed by a 2-h infusion sustained the hypotension and was associated with leukopenia and thrombocytopenia. Ibuprofen given at the mid-point of the infusion reversed the changes in all hemodynamic parameters, but had no effect on the leukopenia or thrombocytopenia. Tumor necrosis factor (TNF) also induced a shock-like state in rabbits. When the dose of IL-1 or TNF was reduced to $1 \mu \mathrm{g} / \mathrm{kg}$, no hemodynamic changes were observed; however, the combination of these low doses of both cytokines resulted in a profound shock-like state including histological evidence of severe pulmonary edema and hemorrhage. Pretreatment with ibuprofen prevented the hemodynamic, leukocyte, and platelet changes induced by the low-dose cytokine combination, and ameliorated the pulmonary tissue damage. These results demonstrate that IL-1, like TNF, possesses the ability to induce hemodynamic and hematological changes typical of septic shock, and that the combination of IL-1 and TNF is more potent than either agent alone. These effects seem to require cyclooxygenase products, and suggest that intravenous cyclooxygenase inhibitors may be of therapeutic value in patients with IL-1/TNF-mediated shock.
\end{abstract}

\section{Introduction}

The polypeptide interleukin 1 (IL-1) mediates several systemic changes associated with infection and injury such as fever, neutrophilia, increased hepatic acute phase protein synthesis, hypoferremia, and elevated corticosteroid levels (1-3). Recombinant IL-1 (beta or alpha forms) have confirmed earlier studies that implicated IL-1 as an important mediator of these

Address reprint requests to Dr. Charles A. Dinarello, New England Medical Center Hospital, 750 Washington St., Boston, MA 02111.

Received for publication 21 July 1987 and in revised form 29 January 1988.

J. Clin. Invest.

(c) The American Society for Clinical Investigation, Inc.

$0021-9738 / 88 / 04 / 1162 / 11 \$ 2.00$

Volume 81, April 1988, 1162-1172 and other acute phase responses, as well as being an immunologically active molecule (4). The synthesis and release of IL-1 from macrophages and other cell types are initiated by microorganisms, endotoxins or exotoxins from a variety of bacteria, or tissue injury. There are two distinct genes coding for IL-1: compared with IL-1-alpha (5), IL-1-beta is the predominant IL-1 and a major product of human monocytes, accounting for $1-2 \%$ of the total polyadenylated RNA after stimulation (6). The concentrations of gram-negative bacterial endotoxin or toxic shock syndrome toxin from Staphylococcus aureus that stimulate human IL-1 production in vitro are low (50-500 $\mathrm{pg} / \mathrm{ml})(7,8)$, and recent data demonstrate that clinically relevant concentrations of purified C5a and C5a desarg also induce human IL-1 release (9).

The production of IL-1 becomes an important consideration in many disease processes. Humans are particularly sensitive in that elevated plasma levels can be measured in patients with a variety of febrile diseases (10), after hemodialysis (11), and in normal human subjects after strenuous exercise (12) or ovulation (10). In rabbits, IL-1 has been demonstrated in the circulation as an endogenous pyrogen after the injection of submicrogram amounts of endotoxin, other pyrogenic toxins, or synthetic adjuvants (1).

There is now considerable evidence that many of the biological and physiological consequences of bacterial sepsis are due to the release and activity of polypeptides such as IL-1 and tumor necrosis factor (TNF). ${ }^{1}$ TNF (also known as cachectin) has recently been implicated as a mediator of fatal endotoxin shock $(13,14)$. We now report that IL-1 (beta or alpha), which shares no amino acid homology with TNF, induces hypotension and several hemodynamic and hematological parameters characteristic of septic shock. The hemodynamic alterations caused by IL-1 seem to require cyclooxygenase products. Because IL-1 and TNF are both produced in animals and humans exposed to endotoxins, we also studied the effect of the combination of IL-1 and TNF in the rabbit model; the dramatic hemodynamic and histological changes induced by the combination of these cytokines were also prevented by pretreatment with a single injection of the cyclooxygenase inhibitor, ibuprofen.

\section{Methods}

Rabbit model. The rabbit was used in the present studies because its sensitivity to the pyrogenic and metabolic effects of endotoxins are similar to those of human subjects (15), and also because rabbits respond to human IL-1. Female New Zealand rabbits $(5 \mathrm{~kg})$ were anes-

1. Abbreviations used in this paper: $\mathrm{CO}$, cardiac output; CVP, central venous pressure; HR, heart rate; MAP, mean arterial pressure; SVR, systemic vascular resistance; TNF, tumor necrosis factor; WBC, white blood cells. 
thetized with a single injection of $4 \mathrm{mg} / \mathrm{kg}$ xylazine and $10 \mathrm{mg} / \mathrm{kg}$ ketamine. This combination of nonbarbiturates has been used in previous studies in models of septic shock in which experimentally induced changes in hemodynamic parameters were unaffected by these anesthetics (16). Catheters were placed in the left carotid artery (PE-50), the pulmonary artery (No. 3 French Swan-Ganz), and the superior vena cava (PE-50) to continuously record arterial and central venous pressure (CVP) and to measure cardiac output (CO) every 10 $\mathrm{min}$. After the insertion of the catheters, hemodynamic changes were monitored for $60 \mathrm{~min}$ to determine baseline levels. It is important to the model used in this study that the rabbits receiving IL-1 or TNF did not require further anesthesia. During the experiments, blood samples removed from the carotid catheter were replaced by the same volume of saline. The total fluid (saline) administered during the study was 6 $\mathrm{ml} / \mathrm{kg}$ per $\mathrm{h}$. CO was measured by the thermodilution method; systemic vascular resistance (SVR) was calculated as follows: (mean arterial pressure [MAP] - CVP) $80 / \mathrm{CO}\left(\mathrm{dyn} \cdot \mathrm{s} \cdot \mathrm{cm}^{-5}\right.$ ). IL-1 (or TNF) was injected into the CVP as a bolus over $1 \mathrm{~min}$. Ibuprofen was kindly supplied by the Upjohn Co., Kalamazoo, MI as a sterile solution for intravenous use. $10 \mathrm{mg} / \mathrm{kg}$ ibuprofen was given through a lateral ear vein over $1 \mathrm{~min}$. Blood was withdrawn from the carotid artery catheter for leukocyte and platelet counts.

$I L-1$ and $T N F$. Human recombinant IL-1 (beta) expressed from amino acids $112-269(6,17)$ was used in these studies. The preparation contained $60 \mathrm{pg}$ of endotoxin per mg of IL-1 as measured in the Limulus test. This IL-1 produced monophasic fevers of $1.26 \pm 0.08^{\circ} \mathrm{C}$ (mean \pm SEM) in nine rabbits after $500 \mathrm{ng} / \mathrm{kg}$ (17). Both the pyrogenicity and induction of hypotension of the IL-1 preparation used in these studies were destroyed at $70^{\circ} \mathrm{C}$ for $30 \mathrm{~min}$. Recombinant human IL-1-alpha (18) was a kind gift of Dr. Peter Lomedico, HoffmannLaRoche Inc., Nutley, NJ, and Dr. Alan Shaw, Biogen, Geneva, Switzerland. Human recombinant TNF was supplied by Genentech, Inc., South San Francisco, CA and was the same lot as previously described in pyrogen studies (19).

Histological studies. $3 \mathrm{~h}$ after the beginning of cytokine infusions, rabbits were killed with pentobarbital; the tissues were removed, cut $\left(\sim 0.5 \mathrm{~cm}^{3}\right)$, and fixed in buffered ( $\left.\mathrm{pH} 7.4\right) 10 \%$ formalin. Tissues were dehydrated, imbedded in Parablast (Monoject, St. Louis, MO), cut into 3-4- $\mu \mathrm{m}$ sections, and mounted. After deparafinizing, tissues were stained with hematoxylin and eosin.

Statistical analyses. Statistical analyses were determined using the ANOVA one-way analysis of variance, in which the postcytokine values of an experimental group at a particular time point were compared with the values of that group at time zero (immediately before injection). The values of various hemodynamic parameters in six rabbits given saline during the 3 -h period were not different $(P>0.05)$ from the values at time zero.

\section{Results}

A single injection of $I L-1$ induces hypotension and prevention by intravenous ibuprofen. As shown in Fig. $1 A$, rabbits given a saline injection remained hemodynamically stable throughout the 3-h period. MAP for six rabbits was $64 \pm 2.9 \mathrm{mmHg}$ (SD) at $t=-60 \mathrm{~min} ; 63.2 \pm 3.3$ at $t=0 \mathrm{~min}$ (saline injection); 65.0 \pm 3.3 at $t=+60 \mathrm{~min} ; 68 \pm 4.4$ at $t=+120 \mathrm{~min}$; and $65.8 \pm 5.1$ at $t$ $=+180 \mathrm{~min}$. Other hemodynamic parameters were also not statistically significant from measurements before the saline injection. The effect of a bolus injection of IL-1-beta on hemodynamic parameters in four rabbits is shown in Fig. $1 B$. MAP began to fall within $10-15 \mathrm{~min}$. MAP reached a maximal decrease to $45.5 \pm 5.3 \mathrm{mmHg}(-23.7 \pm 3.3 \%, P<0.01) 50-60 \mathrm{~min}$ later. In all four rabbits, the MAP fell a minimum of $19.1 \%$. This was followed by a steady increase and a return to preinjection levels by $120-160 \mathrm{~min}$. The decrease in MAP was sta-
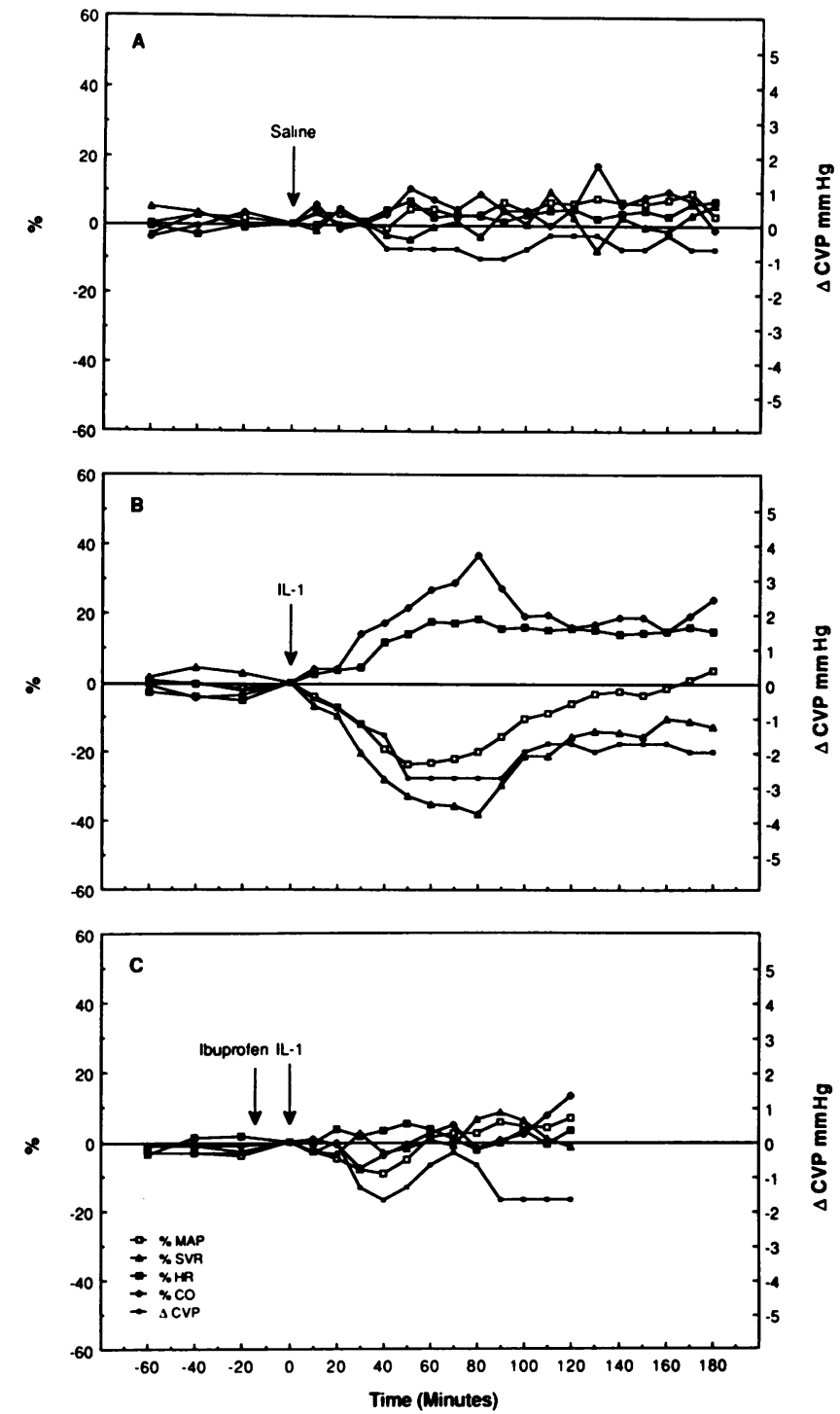

Figure 1. IL-1-induced changes in hemodynamic parameters in rabbits. Mean percent changes from time zero for MAP ( $\square-\square)$, CO $(\diamond-\diamond), \operatorname{SVR}(\Delta-\Delta), \operatorname{HR}(\square-\square)$, and mean change in CVP $(\bullet-\bullet)$ are shown. $(A)$ Control bolus injection of $3 \mathrm{ml}$ physiologic saline into the CVP catheter of six rabbits. $(B)$ Bolus injection (5 $\mu \mathrm{g} / \mathrm{kg}$ ) of IL-1-beta into four rabbits. Maximal percent changes for MAP, CO, SVR, and HR were $-23.7 \pm 3.3(P<0.01),+36.9 \pm 8.1(P$ $<0.01),-38 \pm 1(P<0.01)$, and $+18.2 \pm 1.4(P<0.01)$, respectively, and $-2.8 \pm 0.7 \mathrm{mmHg}(P<0.05)$ for CVP. $(C)$ Three rabbits were pretreated with a bolus injection of intravenous ibuprofen (10 $\mathrm{mg} / \mathrm{kg}$ ) $15 \mathrm{~min}$ before the injection of IL-1. The decreases in MAP and CVP, to $-9.4 \pm 2.4 \%$ and $-1.7 \pm 0.5 \mathrm{mmHg}$, respectively, were not significant $(P>0.05)$.

tistically significant from $t=30$ to $t=90 \mathrm{~min}$ after the IL-1 injection $(P<0.01)$; thereafter, the IL-1-induced hypotension was not significant as readings returned to baseline. The fall in MAP in the IL-1 treated group was significantly greater than the fall in the MAP of six saline-treated control rabbits at $t$ $=30$ to $t=60 \mathrm{~min}(P<0.01)$ and $t=65$ to $t=90 \mathrm{~min}(P$ $<0.05$ ). The rapidity of IL-1-induced hypotension was consistent with the clearance of IL-1 from the circulation after a 
bolus injection. Using ${ }^{125} \mathrm{I}$-labeled IL-1, the plasma half-life was $\sim 6 \mathrm{~min}$ as measured previously (20).

Associated with the fall in arterial blood pressure was a dramatic decrease in SVR $(-38 \pm 1.8 \%)$. By ANOVA analysis to $t=0 \mathrm{~min}$, the significance of the fall in SVR was: $t=10$ to $t$ $=110 \mathrm{~min}, P<0.01 ; t=120$ to $t=150 \mathrm{~min}, P<0.05$. CVP fell while $C O$ and heart rate (HR) increased, and these reached similar levels of significance during these times. After reaching maximal change (60-80 $\mathrm{min}$ ), these parameters also steadily returned towards preinjection levels. A bolus injection of IL-1 (alpha) $(5 \mu \mathrm{g} / \mathrm{kg})$ in two rabbits produced similar results (data not shown). We next pretreated three rabbits with an intravenous injection of ibuprofen. After $15 \mathrm{~min}$, during which time there were no significant changes in hemodynamic parameters, the IL-1-induced hypotension was averted (Fig. $1 \mathrm{C}$ ). The change in MAP for this group ( $-9.4 \pm 2.4 \%)$ was not significant $(P>0.05)$ from baseline measurements, nor were the changes in other hemodynamic parameters.

Effect of a bolus injection of IL-1 followed by constant infusion of the cytokine. In order to more closely simulate a clinical situation of infection or injury, in which IL-1 production is likely sustained for several hours, rabbits were given a bolus injection followed by a 2-h infusion of IL-1. Initial studies indicated that a bolus injection of $1 \mu \mathrm{g} / \mathrm{kg}$, followed by $5 \mathrm{ng} / \mathrm{kg}$ per min constant infusion for $2 \mathrm{~h}$ did not affect any hemodynamic parameter. We doubled this dose and as depicted in Fig. $2 A$, a small decrease in MAP was observed $(-8 \% \pm 1.8$ at $t=90$ $\min , P<0.01)$ in rabbits given an IL-1 bolus injection of 2 $\mu \mathrm{g} / \mathrm{kg}$ followed by a constant infusion of $10 \mathrm{ng} / \mathrm{kg}$ per min. During this time, peripheral white blood cells (WBC) and platelets decreased. When the dose of the bolus injection and constant infusion was increased 2.5-fold (to $5 \mu \mathrm{g} / \mathrm{kg}$ bolus followed by $25 \mathrm{ng} / \mathrm{kg}$ per min), hypotension was sustained (Fig. 2 $B$ ). The MAP was depressed for $90 \mathrm{~min}$ and began to slowly increase $40 \mathrm{~min}$ after the infusion was stopped. The hypotension was maximal 90-120 min after the injection. The fall in MAP was significant, from $t=50$ to $t=180 \mathrm{~min}(P<0.01)$ when compared with either the values of the saline control at the same time point or the preinjection values. The maximal fall $(-33.1 \pm 2.1 \%, P<0.01)$ occurred $100 \mathrm{~min}$ after the IL-1 injection and initiation of the infusion. Changes in $\mathrm{HR}, \mathrm{CO}$, SVR, and CVP were similarly sustained and significant $(P$ $<0.01)$. During this time, peripheral leukocyte and platelet counts fell $(-75 \pm 1.3 \%$ and $-33 \pm 4.7 \%$, respectively, at $120 \mathrm{~min}$ ).

We repeated these experiments in another group of rabbits, and observed the same changes in WBC and platelet counts, as well as hemodynamic changes. However, the hemodynamic changes were reversed by a single injection of ibuprofen administered at the midpoint of the IL-1 infusion (Fig. $2 \mathrm{C}$ ). Despite the continued infusion of IL-1, blood pressure, SVR, and CVP abruptly began to rise, and $\mathrm{CO}$ fell towards baseline. Although the reversal of hemodynamic changes took place within $10 \mathrm{~min}$ after the injection of ibuprofen, leukocyte and platelet counts remained low for the 3-h period.

During the constant infusion experiments, there was no evidence of hemoconcentration as measured by the hematocrit. When compared with control rabbits receiving saline, IL-1-treated rabbits required no further doses of anesthetic (mean dose $50 \mathrm{mg} / \mathrm{kg}$ ketamine for control group vs. $10 \mathrm{mg} / \mathrm{kg}$ for all IL-1 groups). This observation is consistent with the fact
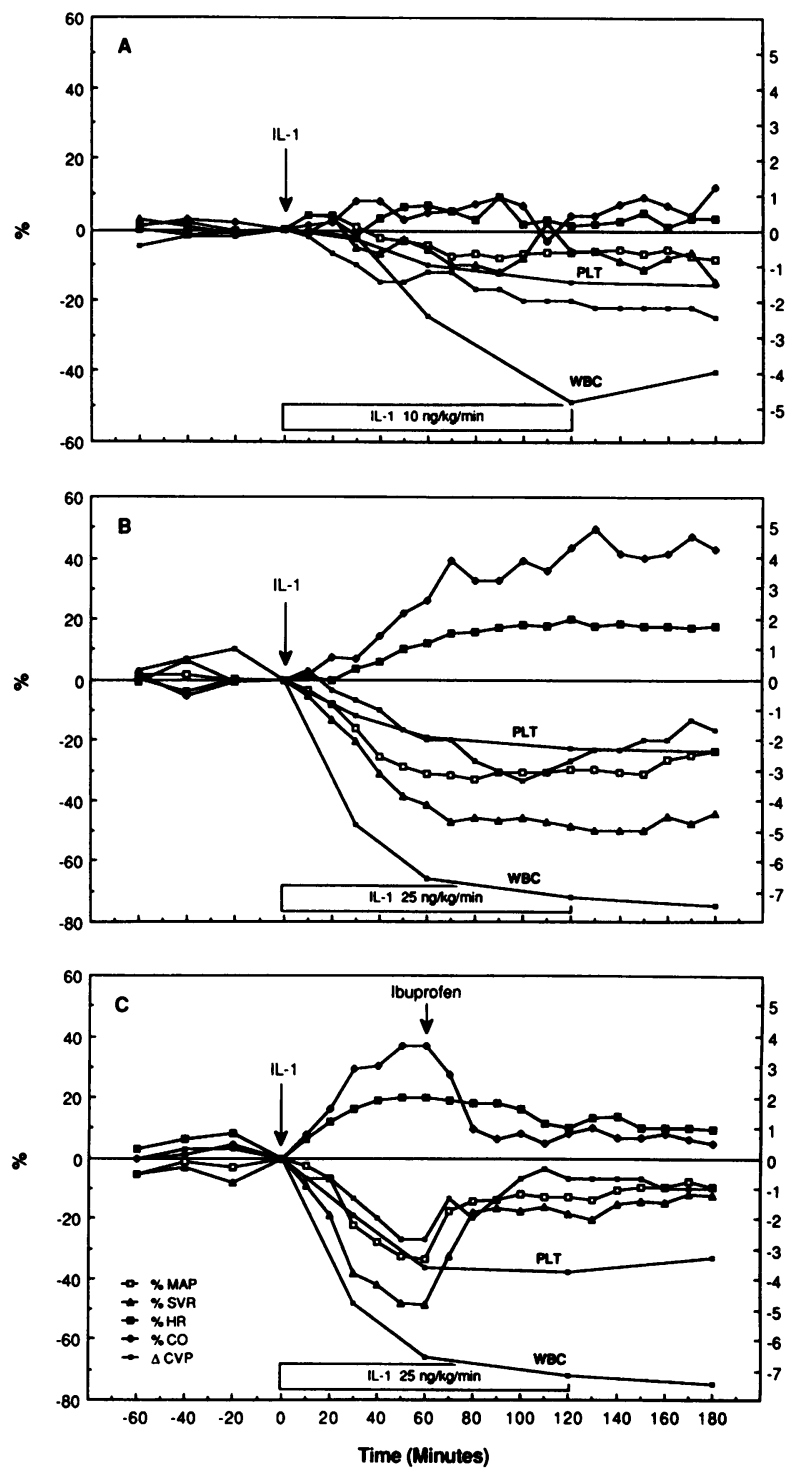

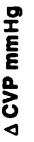

Figure 2. Effect of continuous infusion of IL-1. (A) Mean percent changes in hemodynamic, WBC, and platelets in three rabbits given a bolus injection of IL-1 $(2 \mu \mathrm{g} / \mathrm{kg})$ into the central venous catheter followed by an intravenous infusion ( $10 \mathrm{ng} / \mathrm{kg}$ per $\mathrm{min}$ ) for $2 \mathrm{~h}$ through a lateral ear vein. $(B)$ Mean percent changes in four rabbits given a bolus injection of $5 \mu \mathrm{g} / \mathrm{kg}$ followed by a continuous infusion of $25 \mathrm{ng} / \mathrm{kg}$ per min. During the infusion, the mean maximal percent changes for MAP, CO, SVR, and HR were $-33 \pm 1.7(P<0.01)$, $+49.5 \pm 4.1(P<0.05),-49.9 \pm 1(P<0.01)$, and $+19.9 \pm 3.6(P$ $<0.05)$, respectively. The maximal mean change in CVP was $-3.3 \pm 0.5 \mathrm{mmHg}(P<0.05)$. (C) The effect of intravenous ibuprofen in three rabbits at the mid-point of the infusion. The mean maximal percent changes for MAP, CO, SVR, and HR before the injection of ibuprofen were $-33.4 \pm 1.4(P<0.01),+37.1 \pm 1.1(P<0.01)$, $-48.4 \pm 1.2(P<0.01)$ and $+19.9 \pm 3.6(P<0.05)$, respectively. The maximal mean change in CVP was $-2.7 \pm 0.3(P<0.05)$. The platelet and WBC counts are shown at the times indicated.

that IL-1 increases hourly slow-wave sleep in rabbits and competitively inhibits the binding of opioids to brain synaptosomes in vitro $(21,22)$. Ibuprofen treatment (either before or during IL-1 infusions) had no effect on this finding. 
Effect of TNF in the rabbit model. Previous studies have established that recombinant human IL-1-beta and recombinant human TNF are equipotent as endogenous pyrogens when assayed in rabbits (19). We next administered TNF to compare the hemodynamic effects of this cytokine in our rabbit model. As shown in Fig. $3 \mathrm{~A}$, a single bolus injection of TNF at $1 \mu \mathrm{g} / \mathrm{kg}$ followed by a constant infusion of $5 \mathrm{ng} / \mathrm{kg}$ per min had no effect on hemodynamic parameters. In contrast, a single bolus injection of $5 \mu \mathrm{g} / \mathrm{kg}$ (Fig. $3 \mathrm{~B}$ ) induced sustained hypotension, decreased SVR, decreased CVP, and elevated HR and $\mathrm{CO}(P<0.01$ for all parameters). The hemodynamic effects of this single injection of TNF were comparable with those observed with a bolus injection of IL-1 $(5 \mu \mathrm{g} / \mathrm{kg})$ plus a constant infusion at $25 \mathrm{ng} / \mathrm{kg}$ per min (compare Fig. $2 B$ with Fig. $3 \mathrm{~B}$ ). Because this bolus dose of TNF induces circulating levels of IL-1 in rabbits (19), we speculated that the sustained shock-like state induced by a single dose of TNF might be the result of the combination of TNF itself plus IL-1 induced by TNF in these rabbits.

Synergism of IL-1 and TNF in producing a shock-like state and its prevention by intravenous ibuprofen. As shown above in Figs. $2 A$ and $3 A$, low doses of IL-1 $(2 \mu \mathrm{g} / \mathrm{kg}$ bolus with 10 $\mathrm{ng} / \mathrm{kg}$ per min constant infusion) or TNF $(1 \mu \mathrm{g} / \mathrm{kg}$ bolus with 5 $\mathrm{ng} / \mathrm{kg}$ per min) did not induce hemodynamic changes by themselves. However, as shown in Fig. $4 A$, the combination of IL-1 plus TNF produced sustained hypotension and other hemodynamic changes consistent with the shock syndrome. For
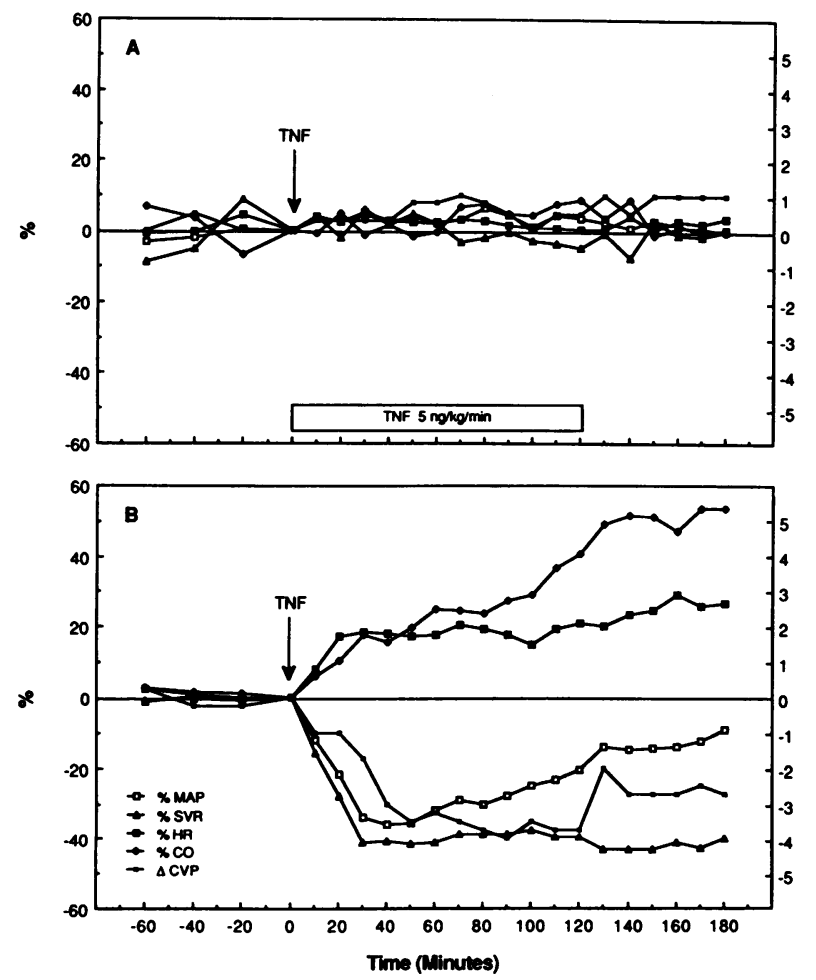

Figure 3. Effect of TNF on hemodynamic parameters. $(A)$ Mean percent hemodynamic changes in three rabbits given a bolus injection of $1 \mu \mathrm{g} / \mathrm{kg}$ followed by a continuous infusion TNF of $5 \mathrm{ng} / \mathrm{kg}$ per min. $(B)$ Mean percent hemodynamic changes in four rabbits given a single bolus injection of $5 \mu \mathrm{g} / \mathrm{kg}$ of TNF. After $20 \mathrm{~min}$, the changes in MAP, CO, SVR, HR, and CVP were significant $(P<0.01)$.

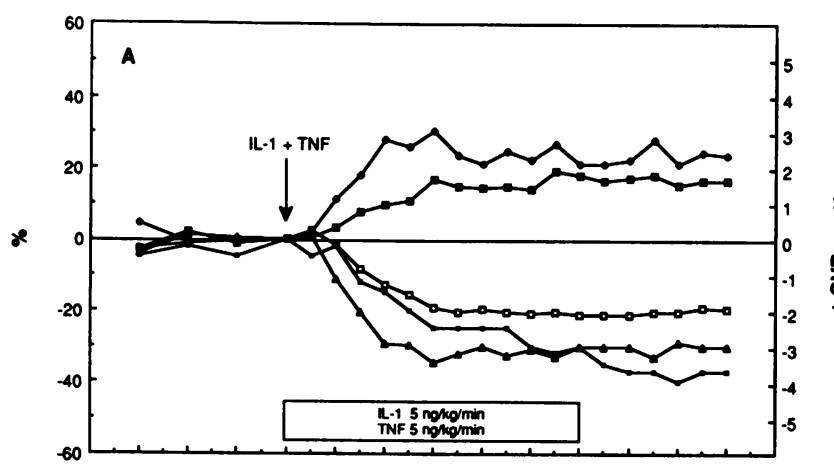

ְ̊.
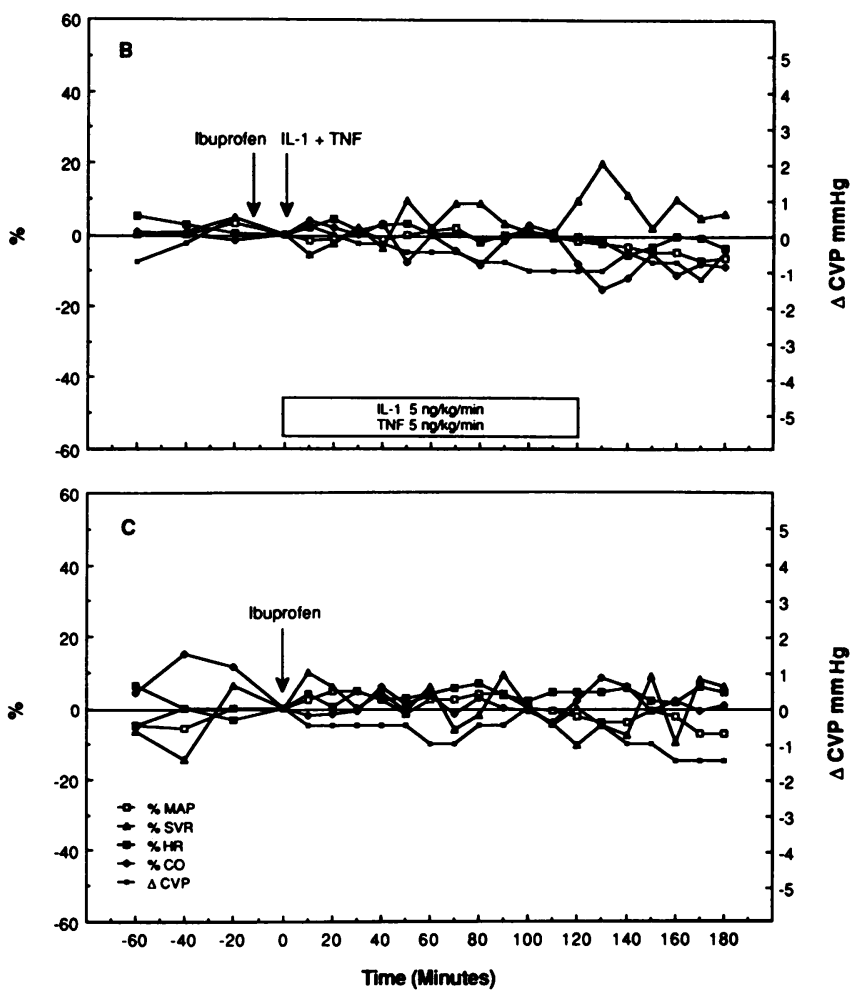

Figure 4. Synergism of IL-1 and TNF infusions and the effect of pretreatment with ibuprofen. $(A)$ Mean percent hemodynamic changes in four rabbits given a bolus injection of IL- 1 at $1 \mu \mathrm{g} / \mathrm{kg}$ plus TNF at $1 \mu \mathrm{g} / \mathrm{kg}$ followed by a constant infusion of each cytokine at $5 \mathrm{ng} / \mathrm{kg}$ per min. (B) Mean percent hemodynamic changes in four rabbits treated as was that shown in Fig. $4 A$ except the rabbits were pretreated with $10 \mathrm{mg} / \mathrm{kg}$ of intravenous ibuprofen $15 \mathrm{~min}$ before the ibuprofenytokine injections. $(C)$ Mean hemodynamic changes in three rabbits given $10 \mathrm{mg} / \mathrm{kg}$ of ibuprofen.

these studies, the dose of IL-1 was reduced to $1 \mu \mathrm{g} / \mathrm{kg}$ bolus injection plus a constant infusion of $5 \mathrm{ng} / \mathrm{kg}$ per min, a dose that had no hemodynamic effect. Thus, the combination of these two cytokines is synergistic and not additive. We next pretreated rabbits with intravenous ibuprofen, injected lowdose IL-1 and TNF, and sustained a constant infusion of both cytokines. As demonstrated in Fig. $4 B$, pretreatment prevented the development of the shock-like state, despite the fact that the cytokines were also infused for the next $2 \mathrm{~h}$. Fig. $4 C$ shows that this dose of ibuprofen has no hemodynamic effect itself. 
The WBC and platelet counts were evaluated in these studies. As shown in Figs. $5 A$ and $B$, similar to the hemodynamic effects, the combination of the two cytokines produced the greatest decreases compared with control values $(P<0.01)$. Pretreatment with intravenous ibuprofen prevented the combination cytokine-induced decreases in WBC and platelets. WBC counts of rabbits receiving saline control or low-dose TNF rose with time. One possible explanation for these increases is that the rabbits were stressed by the preexperiment catheter placements or other stressful aspects of the procedure.

Tissue studies. After each experiment (180 min after the cytokine injection), rabbits were killed, the organs were examined, and various tissues were fixed. Gross changes were observed only in the lungs. The lungs of control rabbits receiving saline appeared pink with occasional areas of subpleural blood (1.5-2 mm diam). The lungs of rabbits receiving low doses of either cytokine showed larger $(0.5-1 \mathrm{~cm}$ diam $)$ areas of hemorrhage on the pleural surface, particularly in rabbits injected with $1 \mu \mathrm{g} / \mathrm{kg}$ of TNF. In contrast, the lungs of rabbits receiving the combination of IL-1 plus TNF appeared liver-like upon
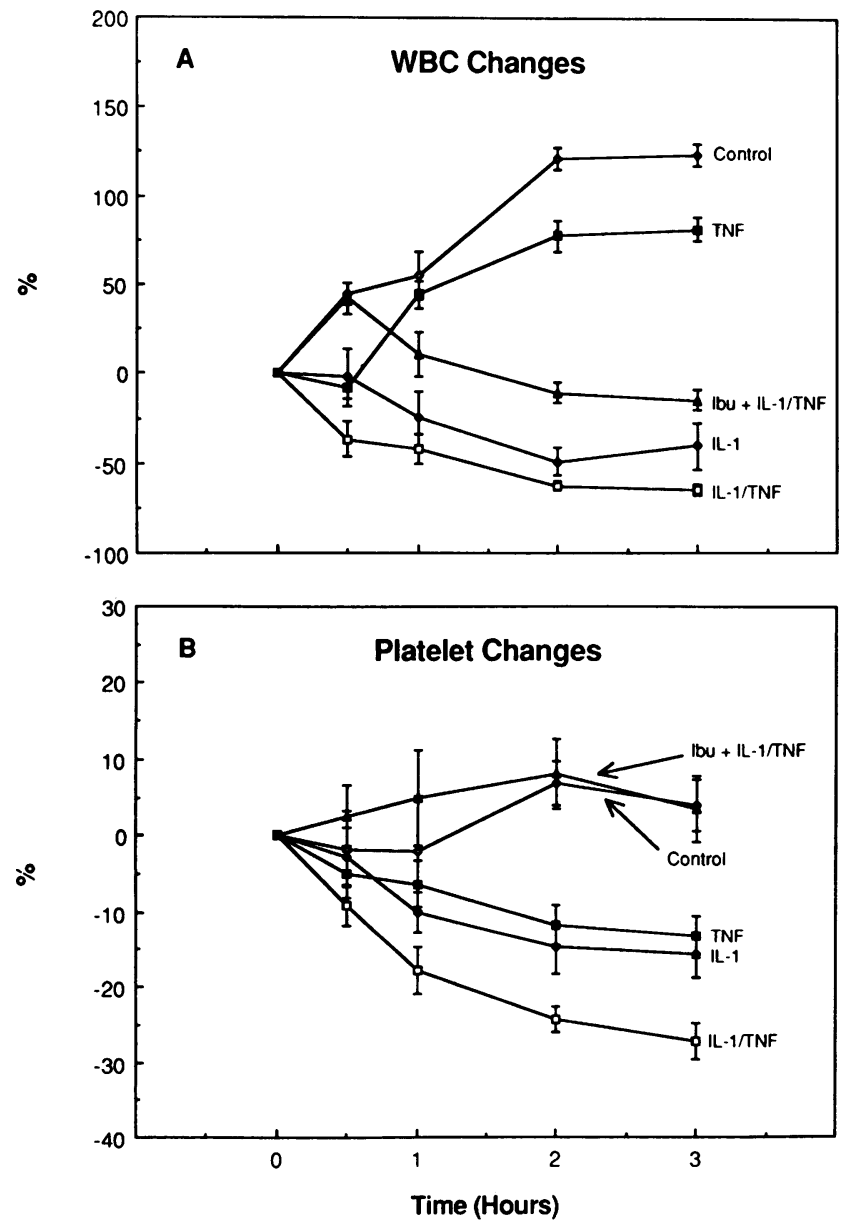

Figure 5. Effect of IL-1 and TNF on circulating WBC and platelets. Mean \pm SEM percent changes in numbers of WBC $(A)$ and platelets $(B)$ in rabbits depicted in Fig. $1 A$ (saline control); Fig. $3 A$ (TNF at 1 $\mu \mathrm{g} / \mathrm{kg}$ ); Fig. $2 A$ (IL-1 at $2 \mu \mathrm{g} / \mathrm{kg}$ ); Fig. $4 A$ (IL-1 at $1 \mu \mathrm{g} / \mathrm{kg}$ plus TNF at $1 \mu \mathrm{g} / \mathrm{kg}$ ); and Fig. $4 B$ (ibuprofen pretreatment followed by 1 $\mu \mathrm{g} / \mathrm{kg}$ each of IL-1 plus TNF). inspection and palpation. This comparison is shown in Fig. 6. In rabbits pretreated with ibuprofen before the combination of cytokines, the lungs showed diffuse surface hemorrhage, but gross hepatization was absent and the lungs were clearly less severely affected than the lungs of rabbits not given ibuprofen.

The gross findings were consistent with the histological sections in the various treatment groups. Figs. $7 A-E$ illustrate the microscopic findings. Figure $7 A$ illustrates the lung of a rabbit used for saline control experiments. The microscopic appearance of lungs from rabbits receiving low-dose IL-1 (2 $\mu \mathrm{g} / \mathrm{kg}$ and $10 \mathrm{ng} / \mathrm{kg}$ per min infusions) showed only an occasional granulocyte (rabbit neutrophils appear eosinophilic) in the alveolar capillary bed (Fig. $7 \mathrm{~B}$ ). In contrast, in the lungs of rabbits given low-dose TNF, there was evidence of red blood cells and granulocytes in the alveolar space and increased numbers of granulocytes in the capillaries (Fig. $7 \mathrm{C}$ ). Fig. $7 \mathrm{D}$ is from a rabbit that received the combination of cytokines. The alveolar space is full of protein, red blood cells, and WBC. The effect of ibuprofen pretreatment of rabbits receiving IL-1 plus TNF is shown in Figure $7 \mathrm{E}$. The massive transudate is absent, but cellular infiltration can still be observed.

\section{Discussion}

Animal models for the induction of septic shock usually employ large $(\mu \mathrm{g}-\mathrm{mg} / \mathrm{kg})$ doses of endotoxins or live organisms, and that under these conditions, IL-1 and TNF are produced. Although TNF induces shock in rats $(14,23)$, the present studies demonstrate that IL-1 is also capable of inducing hypotension and hemodynamic changes typical of shock in rabbits. The onset, maximal effect, and resolution of hypotension induced by a single bolus injection of IL- 1 is nearly identical to the time course of the pyrogenic response to one-tenth the dose (17). IL-1 causes fever by its ability to increase AA metabolites from the specialized vascular endothelial organs of the laminia terminalis of the hypothalamus (24-26). It seems likely that the vascular endothelium is also the target for IL-1 in the pathogenesis of hypotension. This is supported by evidence that IL-1 induces increased endothelial cell production of $\mathrm{PGE}_{2}, \mathrm{PGI}_{2}$, and platelet activating factor (27-29); in addition, IL-1 induces increased neutrophil and macrophage thromboxane $B_{2}$ (TXB) release (30). A sudden increase in some of these substances may induce leukocyte aggregation and systemic vasodilation, which would account for the dramatic decrease in SVR observed in our studies. Experiments have shown that IL-1 stimulates endothelial cell-leukocyte adhesion (31), and in addition to TXB production, this may explain the rapid drop in leukocyte counts. This is supported by the large accumulation of neutrophils adhering to the lung endothelium, that has been observed after IL-1 injected into rabbits (32).

One goal of the present study was to compare the IL-1-induced hemodynamic changes with those induced by recombinant human TNF in the same animal model. In recent studies using pentobarbital-anesthetized dogs, a dose of human TNF of $10 \mu \mathrm{g} / \mathrm{kg}$ produced a reversible $30 \%$ fall in MAP (33); this is nearly 50 times less than the amount of TNF required to produce hypotension in rats (14). Although the fever-producing ability of human IL-1 or TNF in rabbits is similar on a weight basis (19), a single bolus injection of $5 \mu \mathrm{g} / \mathrm{kg}$ of TNF produced 


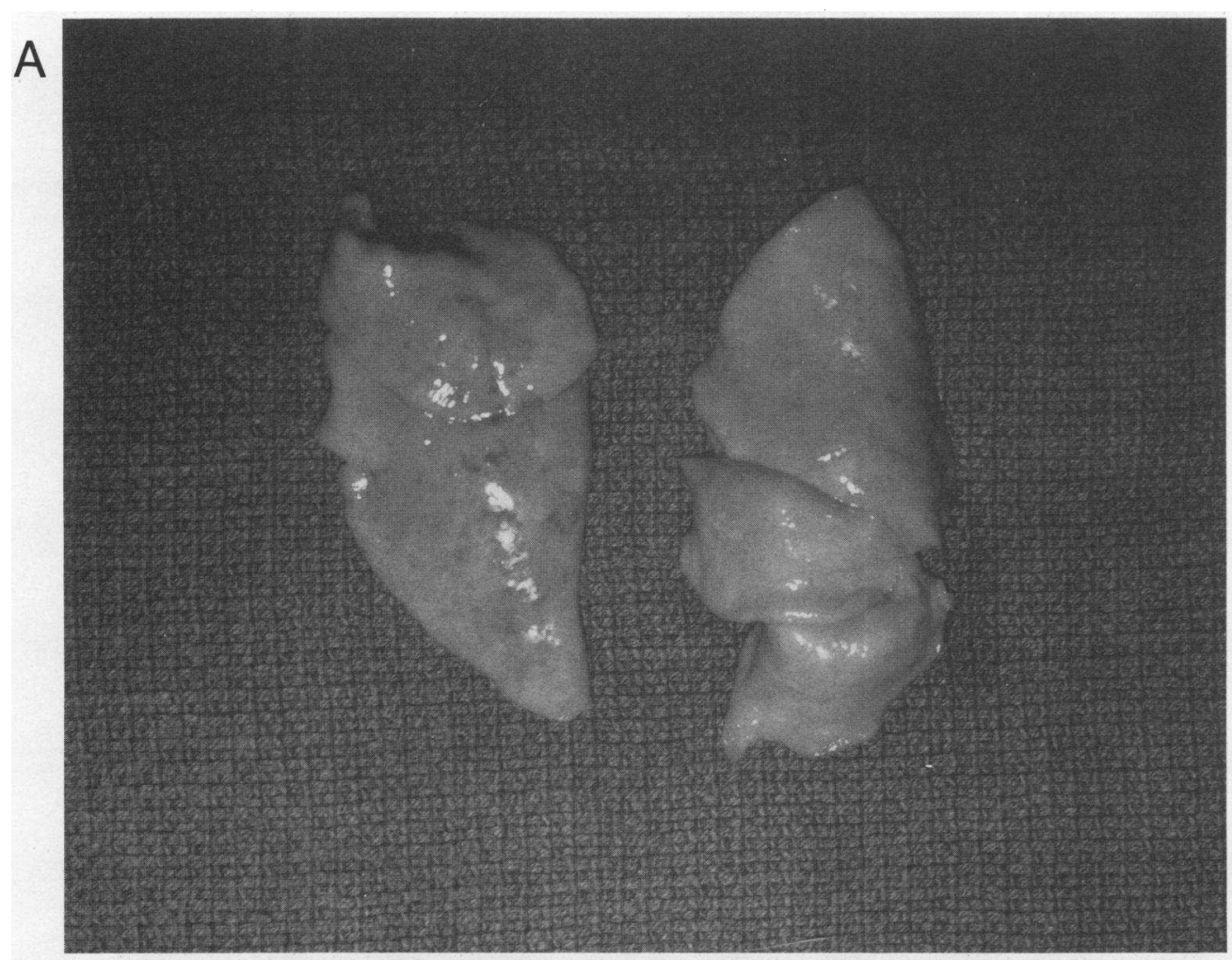

B

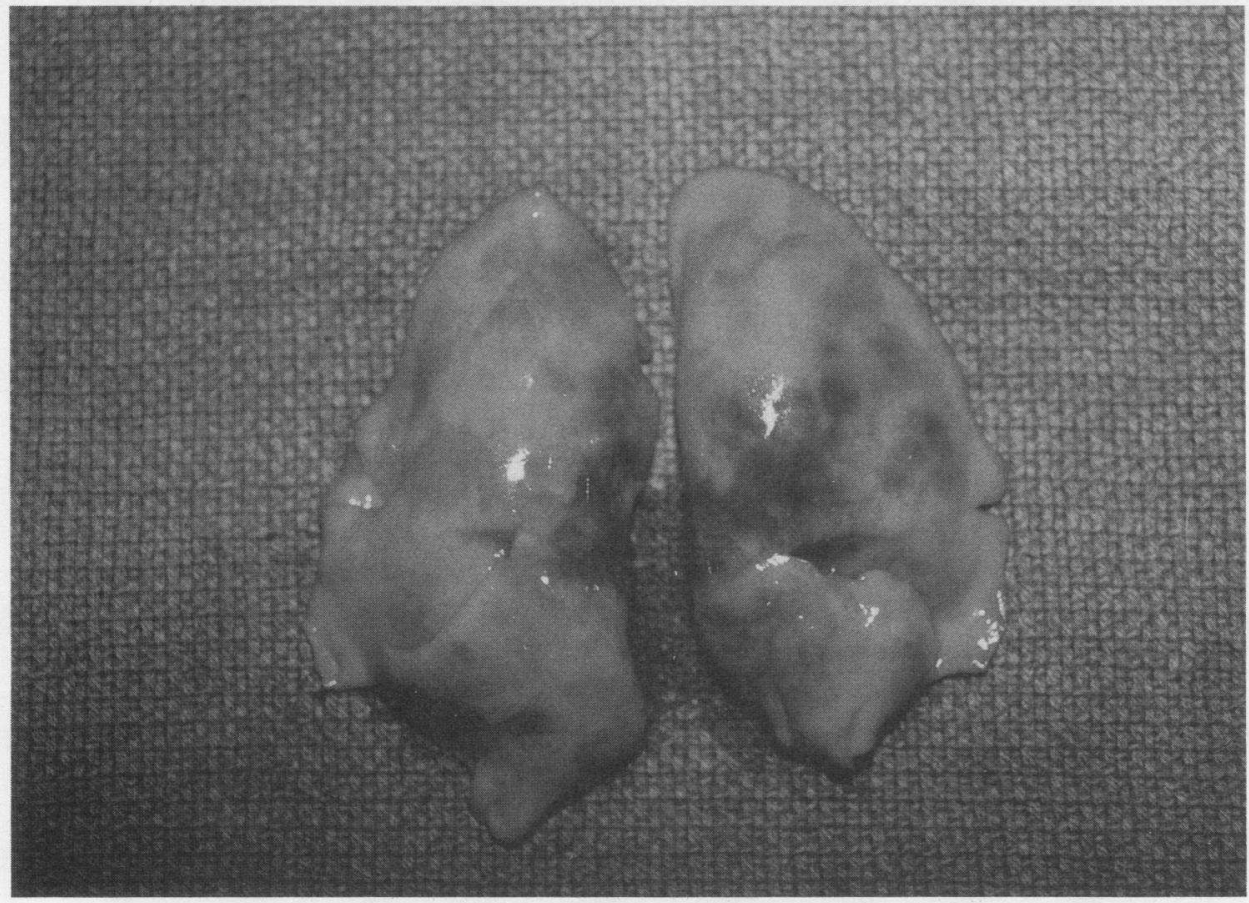

Figure 6. Rabbit lungs after TNF and TNF/IL-1 combination administration. $(A)$ Lungs removed from a rabbit $3 \mathrm{~h}$ after receiving a bolus injection of TNF at $1 \mu \mathrm{g} / \mathrm{kg}$ followed by an infusion at $5 \mathrm{ng} / \mathrm{kg}$ per $\mathrm{min}$.

$(B)$ Lungs removed from a rabbit $3 \mathrm{~h}$ after receiving a bolus injection of TNF plus IL- 1 each at 1 $\mu \mathrm{g} / \mathrm{kg}$ followed by an infusion of each cytokine at $5 \mathrm{ng} / \mathrm{kg}$ per $\mathrm{min}$. a sustained shock-like state in our model and was clearly more potent than the same dose of IL-1. However, since the amount of TNF employed in these studies induces circulating IL-1 in rabbits (19), we speculate that the sustained shock-like state after a single injection of TNF might be due to a combination of TNF and IL-1. This is supported by studies demonstrating the induction of IL-1 from human monocytes (18) and from cultured endothelial cells (34) exposed to TNF. Using the com- bination of both cytokines, which was given in doses that individually produced no hemodynamic changes, we observed a sustained decrease in MAP. The hemodynamic effects of the combination of low-dose IL-1 plus TNF were nearly the same as those produced by a single bolus injection of $5 \mu \mathrm{g} / \mathrm{kg}$ of TNF alone, or by $5 \mu \mathrm{g} / \mathrm{kg}$ of IL-1 plus a constant infusion of IL-1. We conclude from these studies that TNF is more potent than IL-1 in inducing a shock-like state, but that the effect of TNF 

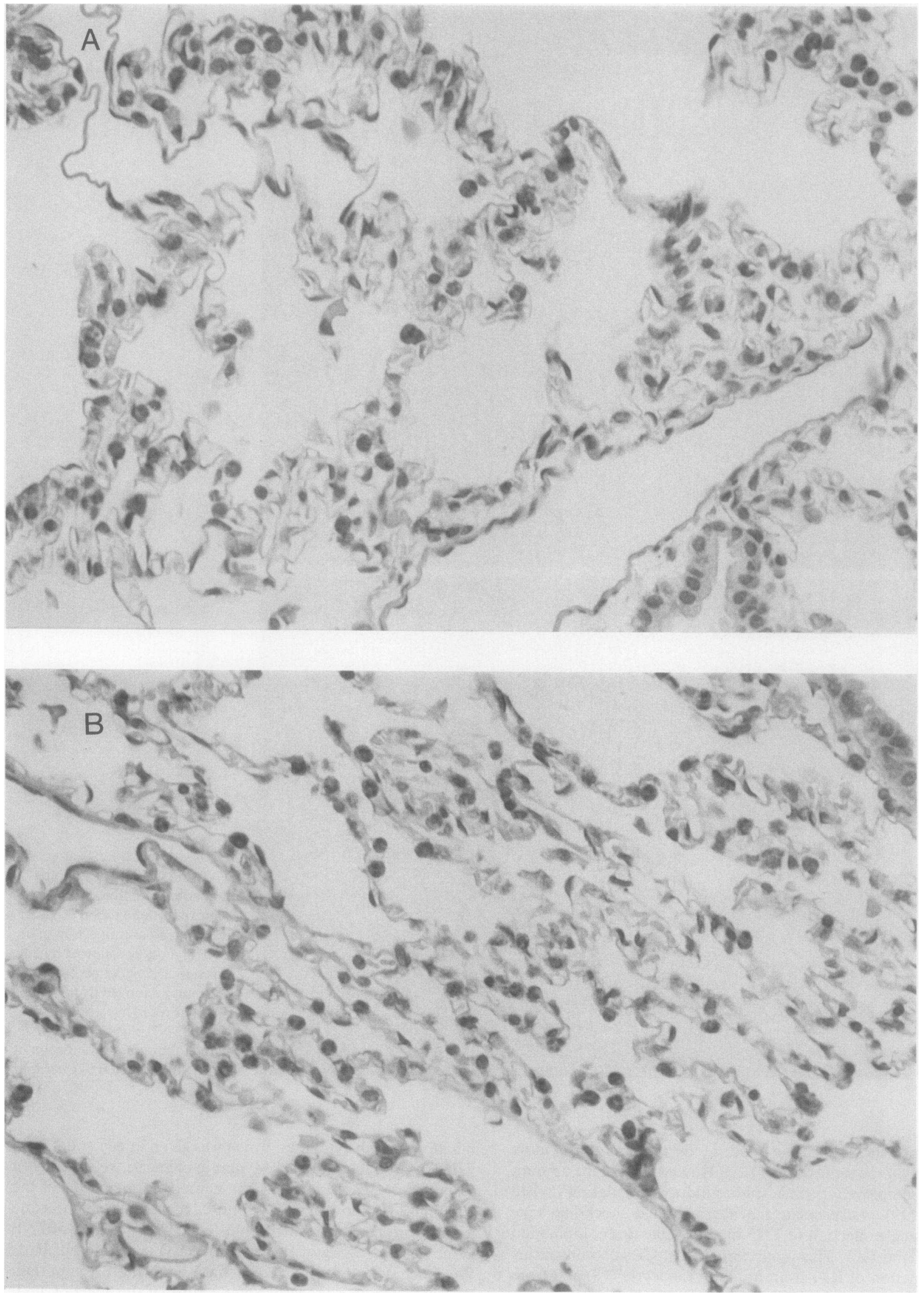

Figure 7 

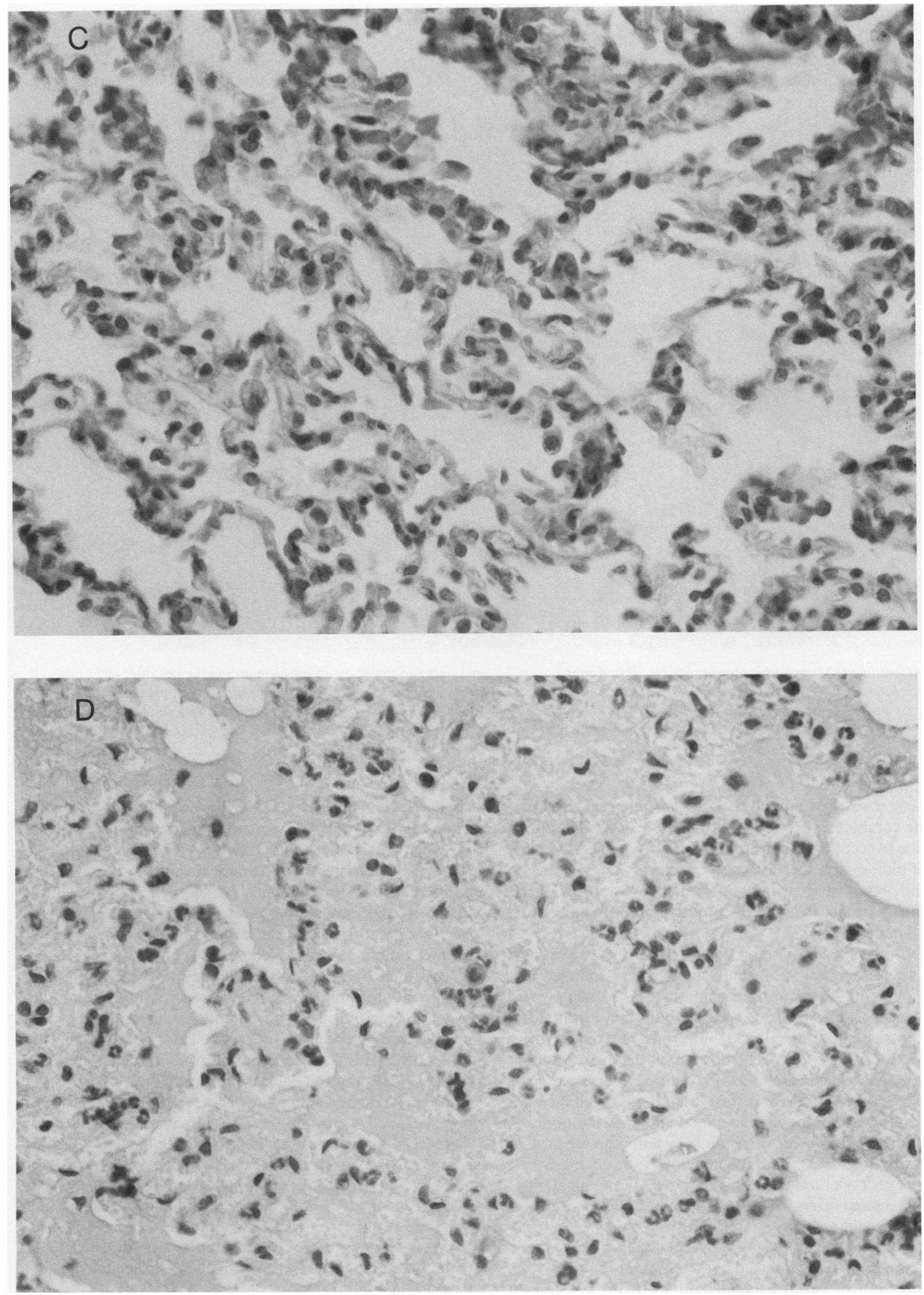


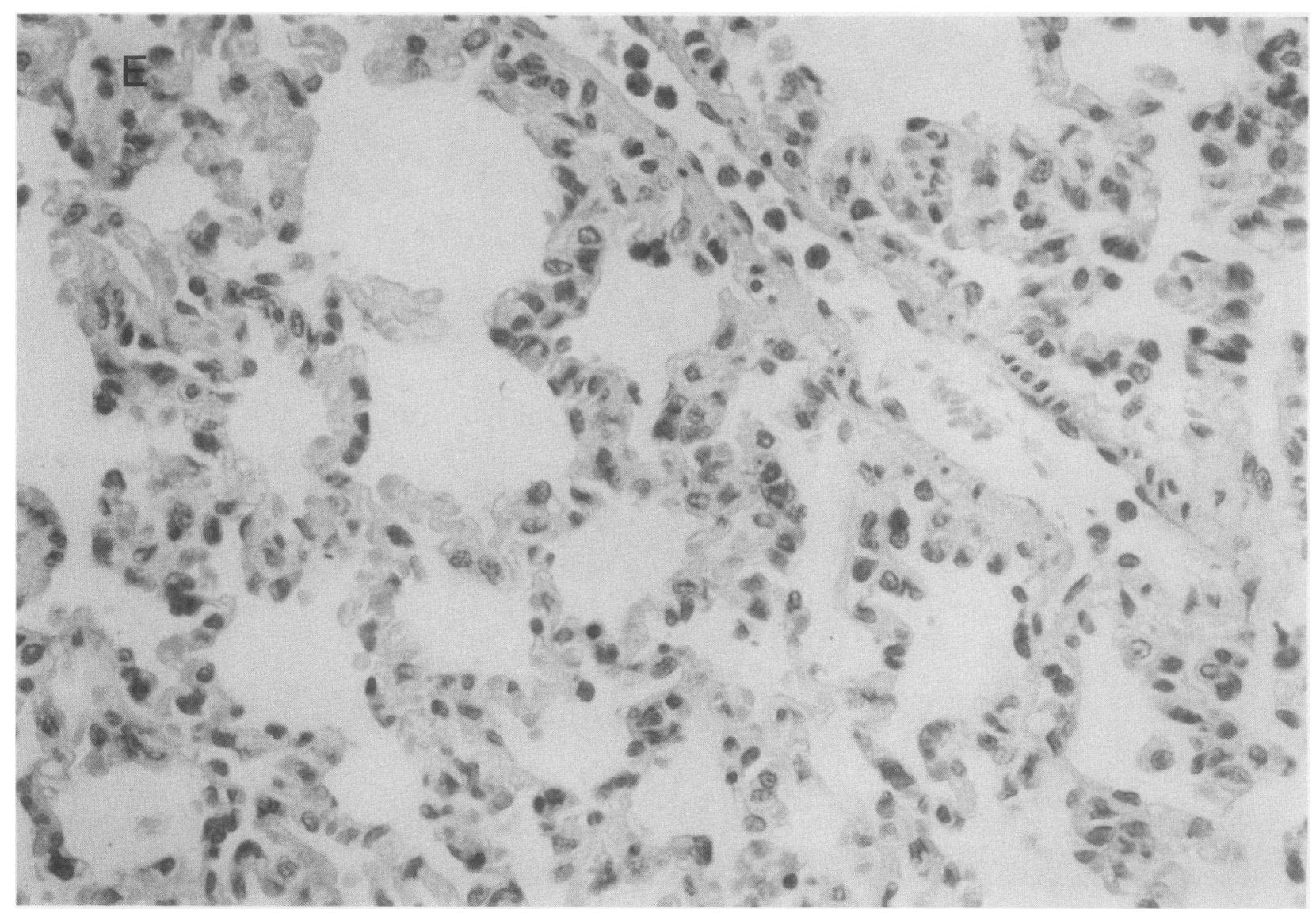

Figure 7. (Continued) Microscopic appearance $(\times 500)$ of rabbit lungs removed at $t=180 \mathrm{~min}$. (A) Rabbit lung from the saline control experiments. (B) Lung from rabbit receiving IL-1 at $2 \mu \mathrm{g} / \mathrm{kg}$ followed by $10 \mathrm{ng} / \mathrm{kg}$ per min infusion. $(C)$ Lung of rabbit given TNF at $1 \mu \mathrm{g} / \mathrm{kg}$ followed by an infusion at $5 \mathrm{ng} / \mathrm{kg}$ per min. (D) Lung from a rabbit who received the combination of cytokines as shown in Fig. $4 A$. $(E)$ Lung from rabbit pretreated with ibuprofen and then given the combination of cytokines as depicted in Fig. $4 B$. (particularly doses that induce IL-1 in vivo) may be, in part, due to the combined effect of TNF plus IL-1. Recent studies support the concept that IL-1 and TNF act synergistically in a variety of biological assays for these cytokines $(35,36)$. Relevant to the present study is the finding that IL-1 and TNF act synergistically on fibroblast $\mathrm{PGE}_{2}$ production (37) and endothelial cell damage (35).

A role for cyclooxygenase products and platelet activating factor in the development of septic shock is well-founded in animal models (38-41) and studies in humans (42); hence, we studied the effects of cyclooxygenase inhibition in our model. A single intravenous injection of ibuprofen prevented the IL-1- and IL-1/TNF-induced hemodynamic changes. Moreover, ibuprofen reversed the shock-like hemodynamic parameters sustained during constant infusions of IL-1. The ability of ibuprofen to avert hemodynamic effects supports the notion that IL-1- and TNF-induced increases in cyclooxygenase products contribute significantly to the hemodynamic changes observed. In a variety of models of septic shock, ibuprofen attenuates the increased levels of TXB, $\mathrm{PGI}_{2}$, and $\mathrm{PGE}_{2}$, as well as hemodynamic changes associated with the shock (43-46). These latter studies suggest that the AA metabolites mediating endotoxin- and cytokine-induced hypotension are similar.

Examination of various tissues (kidney, skin, intestines, liver, and spleen) revealed that the lung was the only organ that was substantially affected by the cytokine infusions in the doses used in these studies. TNF appeared to induce more gross and microscopic lung damage than IL-1; however, the combination of both cytokines produced a dramatic effect, with massive accumulation of protein and cells in the alveolar space. The hemorrhage and hepatization which were observed with the combination of low doses of both cytokines suggest that IL-1 and TNF act together in disrupting the pulmonary vascular endothelium, as has been shown recently in endothelium of the skin (35). Like the hemodynamic effects, the gross and microscopic changes were significantly ameliorated by pretreatment with a single injection of ibuprofen. The IL-1and IL-1/TNF-induced leukopenia and thrombocytopenia was also prevented by ibuprofen. These findings are consistent with experiments showing that ibuprofen reduces neutrophil adherence and responses to chemotactic factors $(47,48)$. This fall in WBC has also been observed in humans during recent studies in which $2-3 \mu \mathrm{g} / \mathrm{kg}$ of intravenous TNF induces a sudden decrease in circulating neutrophils, as well as fever and hypotension (49). Thus, the potential use of intravenous cyclooxygenase inhibitors in clinical situations in which IL-1 and TNF initiate or mediate the shock-like state is suggested by the data presented in this report. 


\section{Acknowledgments}

We wish to acknowledge Dr. John Burke, Dr. Alan Callow, Dr. Peter Libby, and Dr. Sheldon M. Wolff for help and suggestions.

These studies were supported by National Institutes of Health grants AI-15614, GM-21700, and HD-19675.

\section{References}

1. Dinarello, C. A. 1984. Interleukin-1. Rev. Infect. Dis. 6:55-95.

2. Kampschmidt, R. F. 1984. Infection, inflammation, and interleukin-1. Lymphokine Res. 2:97-104.

3. Besedovsky, H., A. del Rey, E. Sorkin, and C. A. Dinarello. 1986. Immunoregulatory feedback between interleukin-1 and glucocorticoid hormones. Science (Wash. DC). 233:652-654.

4. Dinarello, C. A. 1986. Interleukin-1: Amino acid sequences, multiple biological activities, and comparison with tumor necrosis factor. Year Immunol. 2:68-89.

5. Lomedico, P. T., U. Gubler, C. P. Hellman, M. Dukovich, J. G. Giri, Y. E. Pan, K. Collier, R. Semionow, A. O. Chua, and S. B. Mizel. 1984. Cloning and expression of murine interleukin-1 in Escherichia coli. Nature (Lond.). 312:458-462.

6. Auron, P. E., A. C. Webb, L. J. Rosenwasser, S. F. Mucci, A. Rich, S. M. Wolff, and C. A. Dinarello. 1984. Nucleotide sequence of human monocyte interleukin-1 precursor cDNA. Proc. Natl. Acad. Sci. USA. 81:7907-7911.

7. Duff, G. W., and E. Atkins. 1982. The detection of endotoxin by in vitro production of endogenous pyrogen: Comparison with limulus amebocyte lysate gelation. J. Immunol. Methods. 52:323-327.

8. Ikejima, T., C. A. Dinarello, D. M. Gill, and S. M. Wolff. 1983. Induction of human interleukin-1 by a product of Staphylococcus aureus associated with toxic shock syndrome. J. Clin. Invest. 73:1312-1320.

9. Okusawa, S., C. A. Dinarello, K. B. Yancey, S. Endres, T. J. Lawley, M. M. Frank, J. F. Burke, and J. A. Gelfand. 1987. C5a induction of human IL-1: Synergistic effect with endotoxin or intereron-gamma. J. Immunol. 139:2635-2640.

10. Cannon, J. G., and C. A. Dinarello. 1985. Increased plasma interleukin-1 activity in women after ovulation. Science (Wash. DC). 227:1247-1250.

11. Lonnemann G., M. Bingel, K. M. Koch, S. Shaldon, and C. A. Dinarello. 1987. Plasma interleukin-1 activity in humans undergoing hemodialysis with regenerated cellulosic membranes. Lymphokine Res. 6:63-70.

12. Cannon, J. G., and Kluger M. J. 1983. Endogenous pyrogen activity in human plasma after exercise. Science (Wash. DC). 220:617-619.

13. Beutler, B., I. W. Milsark, and A. Cerami. 1985. Passive immunization against cachectin/tumor necrosis factor protects mice from lethal effect of endotoxin. Science (Wash. DC). 229:869-872.

14. Tracey, K. J., B. Beutler, S. F. Lowry, J. Merryweather, S. Wolpe, I. W. Milsark, R. J. Hairi, T. J. Fahey, A. Zentella, J. D. Albert, and A. Cerami. 1986. Shock and tissue injury induced by recombinant human cachectin. Science (Wash. DC). 234:470-473.

15. Wolff, S. M. 1973. Biological effects of bacterial endotoxins in man. J. Infect. Dis. 128:259-270.

16. Simon, G. L., J. A. Gelfand, R. J. Connolly, T. F. O'Donnell, and S. L. Gorbach. 1985. Experimental Bacteroides fragilis bacteremia in a primate model: evidence that Bacteroides fragilis does not promote the septic shock syndrome. J. Trauma. 25:1156-1162.

17. Dinarello, C. A., J. G. Cannon, J. W. Mier, H. A. Bernheim, G. LoPreste, D. L. Lynn, R. N. Love, A. C. Webb, P. E. Auron, R. C. Reuben, A. Rich, S. M. Wolff, and S. D. Putney. 1986. Multiple biological activities of human recombinant interleukin-1. J. Clin. Invest. 77:1734-1739.
18. Gubler, U., A. O. Chua, A. S. Stern, et al. 1986. Recombinant human interleukin-1-alpha: purification and biological characterization. J. Immunol. 136:2492-2498.

19. Dinarello, C. A., J. G. Cannon, S. M. Wolff, H. A. Bernheim, B. Beutler, A. Cerami, I. S. Figari, M. A. Palladino, Jr., and J. V. O'Connor. 1986. Tumor necrosis factor (cachectin) is an endogenous pyrogen and induces interleukin 1. J. Exp. Med. 163:1433-1447.

20. Dinarello, C. A., T. Ikejima, S. J. C. Warner, S. F. Orencole, G. Lonnemann, J. G. Cannon, and P. Libby. 1987. Interleukin-1 induces interleukin-1. I. Induction of circulating interleukin-1 in rabbits in vivo and in human mononuclear cells in vitro. J. Immunol. 139:19021910.

21. Krueger, J. M., J. Walter, C. A. Dinarello, S. M. Wolff, and L. Chedid. 1984. Sleep-promoting effects of endogenous pyrogen (interleukin-1). Am. J. Physiol. 246:R994-R999.

22. Ahmed, M. S., J. Llanos-Q, C. A. Dinarello, and C. M. Blatteis. 1986. Interleukin-1 reduces opioid binding in guinea pig brain. Peptides. 6:1149-1154.

23. Beutler, B., and A. Cerami. 1986. Cachectin and tumor necrosis factor as two sides of the same biological coin. Nature (Lond.). 320:584-590.

24. Blatteis, C. M., S. L. Bealer, W. S. Hunter, J. Llanos-Q, R. A. Ahokas, and T. A. Mashburn, Jr. 1983. Suppression of fever after lesions of the anteroventral third ventricle in guinea pigs. Brain Res. Bull. 11:519-525.

25. Stitt, J. T. 1985. Evidence for the involvement of the organum vasculosum of the laminia terminalis in the febrile responses of rabbits and rats. J. Physiol. 368:501-511.

26. Coceani, F., I. Bishai, J. Lees, and S. Sirko. 1986. Prostaglandin $\mathrm{E}_{2}$ and fever: a continuing debate. Yale J. Biol. Med. 59:169-176.

27. Rossi, V., F. Breviario, P. Ghezzi, E. Dejana, and A. Mantovani. 1985. Interleukin-1 induces prostacyclin in vascular cells. Science (Wash. DC). 229:1174-1177.

28. Dejana, E., F. Breviario, A. Erroi, F. Bussolino, L. Mussoni, M. Gramse, G. Pintucci, B. Casali, C. A. Dinarello, J. Van Damme, and A. Mantovani. 1987. Modulation of endothelial cell functions by different molecular species of interleukin-1. Blood. 69:695-701.

29. Albrightson, C. R., N. L. Baenziger, and P. Needleman. 1985. Exaggerated human vascular cell prostaglandin biosynthesis mediated by monocytes. Role of monokines and interleukin-1. J. Immunol. 135:1872-1877.

30. Conti, P., M. G. Cifone, E. Alesse, M. Reale, C. Fieschi, and C. A. Dinarello. 1986. In vitro enhanced thromboxane B2 release by polymorphonuclear leukocytes and macrophages after treatment with human recombinant interleukin 1. Prostaglandins. 32:111-115.

31. Bevilacqua, M. P., J. S. Pober, M. E. Wheeler, D. Mendrick, R. S. Cotran, and M. A. Gimbrone, Jr. 1985. Interleukin-1 acts on cultured human vascular endothelial cells to increase the adhesion of polymorphonuclear leukocytes, monocytes and related leukocyte cell lines. J. Clin. Invest. 76:2003-2012.

32. Goldblum, S. E., D. A. Cohen, M. N. Gillespie, and C. J. McClain. 1987. Interleukin-1-induced granulocytopenia and pulmonary leukostasis in rabbits. J. Appl. Physiol. 62:122-128.

33. Tracey, K. J., S. F. Lowry, T. J. Fahey, III, J. D. Albert, Y. Fong, D. Hesse, B. Beutler, K. R. Manogue, S. Calvano, H. Wei, A. Cerami, and G. T. Shires. 1987. Cachectin/tumor necrosis factor induces lethal shock and stress hormone responses in the dog. Surg. Gynecol. Obstet. 164:415-422.

34. Libby, P., J. M. Ordovas, K. R. Auger, A. H. Robbins, L. K. Birinyi, and C. A. Dinarello. 1986. Endotoxin and tumor necrosis factor induce interleukin-1 gene expression in adult human vascular endothelial cells. Am. J. Pathol. 124:179-186.

35. Movat, H. Z., C. E. Burrowes, M. I. Cybulsky, and C. A. Dinarello. 1987. Acute inflammation and a Shwartzman-like reaction induced by interleukin-1 and tumor necrosis factor. Synergistic action of the cytokines in the induction of inflammation and microvascular injury. Am. J. Pathol. In press. 
36. Mandrup-Poulsen, T., K. Bendtzen, C. A. Dinarello, and J. Nerup. 1987. Potentiation of IL-1 mediated beta-cell killing by TNF. Human tumor necrosis factor potentiates human interleukin-1 mediated rat pancreatic beta-cell cytotoxicity. J. Immunol. In press.

37. Elias, J. A., K. Gustilo, W. Baeder, and B. Freundlich. 1987. Synergistic stimulation of fibroblast prostaglandin production by recombinant interleukin-1 and tumor necrosis factor. J. Immunol. 138:3812-3816.

38. Halushka, P. V., J. A. Cook, and W. C. Wise. 1983. Beneficial effects of UK 37248, a thromboxane synthetase inhibitor, in experimental endotoxic shock in the rat. Brit. J. Clin. Pharmacol. 15:133S.

39. Slotman, G. J., J. V. Quinn, K. W. Burchard, and D. S. Gann. 1985. Thromboxane, prostacyclin, and the hemodynamic effects of graded bacteremic shock. Circ. Shock. 16:395-413.

40. Wise, W. C., J. A. Cook, and P. V. Halushka. 1981. Implications for thromboxane $\mathrm{A}_{2}$ in the pathogenesis of endotoxic shock. $A d v$. Shock Res. 6:83-88.

41. Chang, S-W., C. O. Feddersen, P. M. Henson, and N. F. Voelkel. 1987. Platelet-activating factor mediates hemodynamic changes and lung injury in endotoxin-treated rats. J. Clin. Invest. 79:14981509.

42. Slotman, G. J., K. W. Burchard, J. J. Williams, A. D'Arezzo, and S. A. Yellin. 1986. Interaction of prostaglandins, activated complement, and granulocytes in clinical sepsis and hypotension. Surgery (St. Louis). 99:744-750.
43. Jacobs, E. R., M. E. Soulsby, R. C. Bone, F. J. Wilson, Jr., and F. C. Hiller. 1982. Ibuprofen in canine endotoxin shock. J. Clin. Invest. 70:536-541.

44. Almqvist, P. M., M. Kuenzig, and S. I. Schwartz. 1984. Treatment of experimental canine endotoxin shock with ibuprofen, a cyclooxygenase inhibitor. Circ. Shock. 13:227-232.

45. Toth, P. D., S. A. Hamburger, and W. V. Judy. 1984. The effects of vasoactive mediator antagonists on endotoxic shock in dogs. Circ. Shock. 12:277-286.

46. Fink, M. P., T. J. MacVittie, and L. C. Casey. 1984. Inhibition of protaglandin synthesis restores normal hemodynamics in canine hyperdynamic sepsis. Ann. Surg. 200:619-626.

47. Maderazo, E. G., S. P. Breaux, and C. L. Woronick. 1986. Protective effects of ibuprofen and methyprednisolone on chemotactic factor-induced transcutaneous hypoxia. J. Pharmacol. Exp. Ther. 238:453-456.

48. Venezio, F. R., C. DeVincenzo, F. Perlman, and J. P. Phair. 1985. Effects of the newer nonsteroidal anti-inflammatory agents, ibuprofen, fenoprofen, and sulindac on neutrophil adherence. J. Infect. Dis. 152:690-694.

49. Chapman, P. B., T. J. Lester, E. S. Casper, J. L. Gabrilove, G. Y. Wong, S. J. Kempin, P. J. Gold, S. Welt, R. S. Warren, H. F. Starnes, S. A. Sherwin, L. J. Old, and H. F. Oettgen. 1987. Clinical pharmacology of recombinant human tumor necrosis factor in patients with advanced cancer. J. Clin. Oncol. 5:1942-1951. 